\title{
Understanding Barriers and Facilitators for Telehealth Implementation in Healthcare Delivery System During COVID-19- Call for Action
}

\author{
Naiya Patel* \\ University of Louisville, School of Public Health and Information Sciences, USA \\ *Corresponding author: Naiya Patel, University of Louisville, School of Public Health and Information Sciences, Louisville, \\ KY, USA
}

\section{ARTICLE INFO}

Received: 慧 August 04, 2021

Published: 业 August 17, 2021

Citation: Naiya Patel. Understanding Barriers and Facilitators for Telehealth Implementation in Healthcare Delivery System During COVID-19- Call for Action. Biomed J Sci \& Tech Res 38(2)-2021. BJSTR. MS.ID.006114.

\begin{abstract}
COVID-19 Pandemic has surfaced several needs in the health care delivery system worldwide. The clinical interactions are turning towards telehealth and remote interactions due to the fact of contracting infection. It is vital to understand underlying barriers and facilitators of telehealth to improve access and utilization of needed healthcare. The disparities in health care utilization already exists among certain chronic conditions group, and pandemic has significantly affected the way people access healthcare services. The paper identifies factors affecting access to healthcare, barriers, and facilitators of healthcare delivery system, and proposes a framework to study telehealth utilization. The call for action paper proposes research methodology at structure, process and outcome level of healthcare delivery system to identify and resolve factors impacting telehealth utilization.
\end{abstract}

Keywords: Telehealth; Access; Utilization of Healthcare; Health Services Research; Public Health

\section{Introduction}

The five dimensions of access are availability, accessibility, accommodation, affordability, and acceptability [1]. Availability is a relationship between the volume of facilities, healthcare supplies, and patient's healthcare needs volume [1]. Accessibility defines the distance between patient and provider, meaning travel time and transportation factors to seek healthcare service [1]. Accommodation defines the relationship between the delivery system, the structure of healthcare facilities set up to accept patients, and the patient's ability to accept it [1]. It includes appointment timings, hours of operations, mobile services, walkin facilities, etc. [1]. Affordability is the relationship between the healthcare provider's charges for the services they provide and the patient's income ability to pay for the services they might seek from those providers [1]. Finally, acceptability means both the patient's and provider's tendency to accept the attributes of each other [1]
Meaning, patients might be willing to go to certain types of facilities, neighborhood, provider gender, or providers' race.

Likewise, the providers might not be willing to accept certain patients holding a kind of insurance coverage they don't accept [1]. It is established that if a problem exists among any dimensions of access, it could influence patients and healthcare delivery systems that are measurable in three ways [1]. First is lowered utilization of services, lower patient satisfaction of the healthcare services they receive, and change in provider practices like reduced patient time [1]. It is evident from the above paragraph that access and utilization are hence interrelated, and access could be measured through utilization [2]. The utilization of healthcare services serves as an indicator to determine whether access to needed healthcare is realized [3]. The frequency of visits to a physician/provider or medical procedure all fall under the utilization indicator of access to healthcare [3]. The structure of a delivery system (accessibility), the 
process of care (accommodation, acceptability, affordability), and health outcomes seem to affect and assess (Figure 1 in Appendix) overall access to care, costs, and quality [4].

The common barriers to access to healthcare are structural (availability, delivery system organization and transportation), financial (insurance coverage, reimbursement levels, and public support), and personal (acceptability, cultural, language, attitudes, and education/income), which affects health and wellbeing of an individual [3]. Measures of access, i.e., utilization of healthcare services and health outcomes, vary as per the equity measures, i.e., barriers to access [3]. Overall, it is evident through Figure 1 in the appendix and literature [5] that healthcare utilization is an indicator of access to healthcare affected by structure, process, and individual characteristics. Nonfinancial barriers to access are common reasons behind unmet need or delayed care among Adults in the United States compared to affordability barriers [6]. Attempts to improve such access through the Affordable Care Act (ACA) Legislation is the one source to improve it as the absence of insurance means no access to the healthcare delivery system [7].

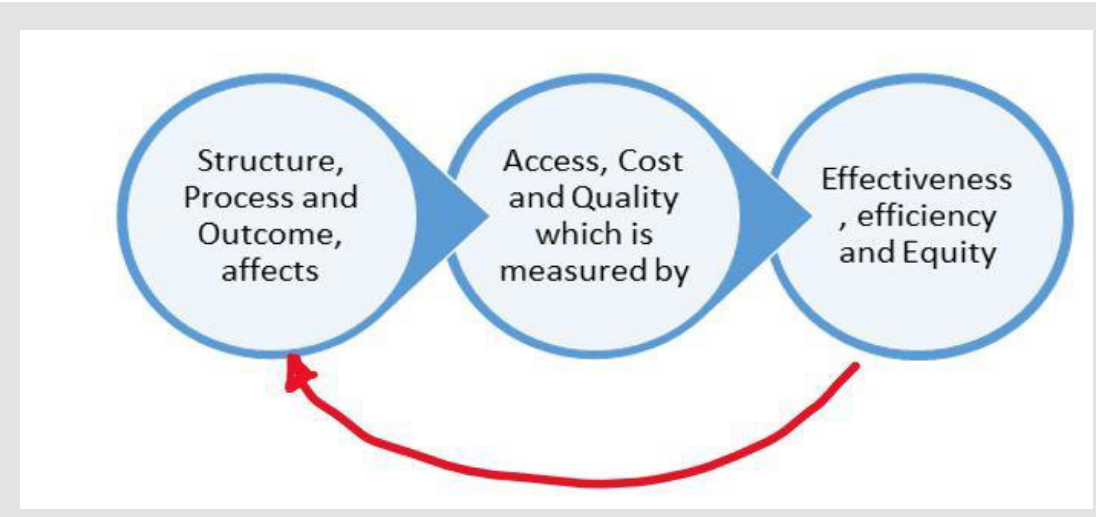

Figure 1: How U.S. healthcare system can be evaluated [4]. Effectiveness, efficiency and equity indirectly measures components of healthcare i.e. Structure, Process and Outcome as they affect Access, Cost and Quality.

However, the non-financial barriers to access couldn't be solved by ACA but by federal and state governments through infrastructure development [6] and changing care delivery patterns like Accountable Care Organizations [8]. The solution to the availability domain issue for access could be increasing the supply of providers and healthcare services in the underserved area [6]. Patients seeking primary care at community healthcare centers are more likely to receive preventive services, Pap smear, vaccinations and, less likely to have low birth weight babies, less likely to visit or seek care in emergency rooms [7]. Several mechanisms through which primary care benefits occur are greater access to needed services and early management of health problems [7]. Greater access to required services improves healthcare services access for disadvantaged population groups who are more prone to lack of regular source of care [7].

Early management of health problems by preventing causes and symptoms like hypertension complications occurs through primary care that could help avoid emergency department visits or hospitalizations and disease progression [7]. Healthcare costs also rise with increased utilization of high-cost services or emergency department visits caused due to unmet medical needs and timely access to care barriers [9]. Integrating medical and non-medical services into a healthcare delivery system could help reduce the cost by improving access to needed care [9]. Accessibility, a nonfinancial access barrier to receiving timely healthcare services, could be improved through telemedicine and transportation services [6]. Alternative payment models have also proven to improve the quality and utilization of healthcare [10]. The access and utilization of healthcare seem to strengthen due to primary care facilities and their providers [7]. Accountable Care Organizations also reduce healthcare costs $[11,8]$, emergency department visits [8], and improve overall healthcare utilization [10].

So, the accommodation domain of access could be improved through open access scheduling to reduce wait time for primary care and or reduce avoidable Emergency Department visits [6]. Disparities in healthcare utilization exist among racial and ethnic groups $[12,13]$. Access to healthcare and insurance coverage constitutes this racial and ethnic disparity [12]. Specific governmental interventions like Medicaid Expansion under ACA legislation have effectively reduced such utilization disparities in the United States $[12,14,15]$. Differences could also be potentially eliminated by managed care programs performing in certain states with vulnerable beneficiaries if enrolled [13]. Increased utilization of acute healthcare services by the homeless population also exists as a disparity compared to other groups [16]. Certain vulnerable groups might also face barriers to access to healthcare due to unmet non-medical needs at an early stage and hence causes an increase in overall healthcare expenditure [16]. Patients and providers also play a vital role in help identifying the barriers to access to care, quality of care, or general issues they face regarding the process of 
healthcare they receive $[17,18]$ It could help reduce the disparity associated with utilization among the vulnerable group of patients with unmet medical needs.

\section{Problem Analysis- Issues with Influencing Telehealth and Healthcare Utilization}

Before the COVID-19 pandemic, disparities in healthcare utilization were evident, while during the pandemic, disparities within the individual healthcare system for telehealth service utilization exists depending on the patient's socio-economic status [19-24]. Several significant barriers from the patient side are disparities in digital access, digital literacy, telehealth awareness, cost \& coverage for telehealth, racial and ethnic discrimination, low income and, rural population $[22,23]$. The structural-level barriers influencing telehealth services are broadband services availability and quality, licensing regulations for providers, and equitable telehealth insurance service reimbursements $[20,21,25]$. The provider-level barriers are insufficient resources to support virtual care [21,22], inability to obtain physical examination vitals, and lab work [26].

In the absence of policies and interventions to improve access to care through telehealth service utilization, these disparities may broaden [19]. Although Telemedicine utilization has improved among population groups with higher income, it has disproportionately reduced among lower-income, education groups of population with specific cultural and political factors playing the role as mediators for the disparity [19]. Currently, a significant barrier to population-level implementation of telehealth during COVID-19 is workforce challenge with a single remote clinician for multiple sites, credentialing, payments/reimbursements, staffing of specialists, and infrastructure in place to implement telehealth effectively [27]. The pandemic has affected Emergency Department visits which might impact the overall health outcome of the population requiring the visit [28]. It is vital to understand the root causes of the decreased Emergency Department visits in pandemic and its impact on overall population health outcomes [28]. It is also essential to determine what impacts provisions of services like telehealth that provide continuity of care. Its implementation leads to improving the cost and quality of healthcare for all types of patients.

\section{Application of Andersen and Aday Model- Empirical Literature}

The U.S. healthcare service continuum could be divided into primary, secondary, and tertiary [4], as depicted in (Figure 2 Appendix). So, it is vital to evaluate and determine the application of any model across the continuum of care to understand the effects on access and utilization of healthcare. The Andersen and Aday Model helps us understand and evaluate the structure process and the outcome along and across the continuum [4]. The conceptual framework proposed by Andersen and Aday inculcates system, institution, and patient/individual level constructs that help determine the relationship and define a problem in health services research [5]. It helps provide descriptive data on the organization (structure) and operation (process) of the healthcare system. It also helps to understand the percent people uninsured, the proportion and distribution of providers, and overall healthcare service utilization [4]. The model helps understand, examine, and evaluate the relationship and impact of one component on the other (Figure 3 Appendix) as depicted by the directions of arrows in the model [5].

\section{Figure 1.1 Continuum of Healthcare Services}

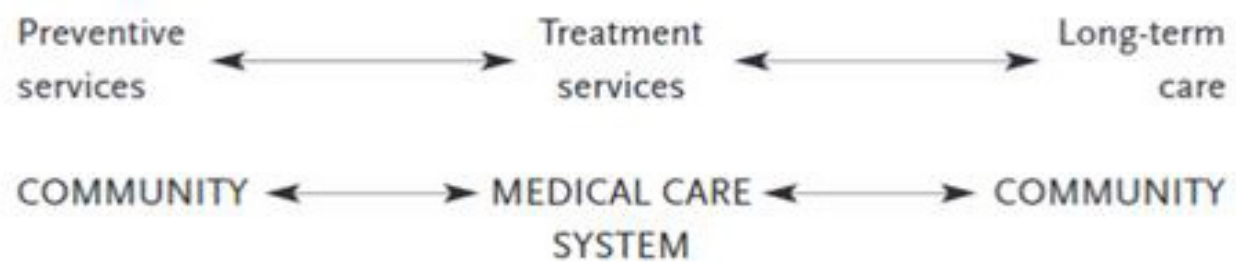

\begin{tabular}{|c|c|c|c|c|c|}
\hline $\begin{array}{l}\text { Community } \\
\text { resources }\end{array}$ & $\begin{array}{l}\text { Public } \\
\text { health } \\
\text { system }\end{array}$ & $\begin{array}{c}\text { Ambulatory } \\
\text { care }\end{array}$ & $\begin{array}{c}\text { Acute } \\
\text { institutional } \\
\text { care }\end{array}$ & $\begin{array}{c}\text { Long-term } \\
\text { institutional } \\
\text { care }\end{array}$ & $\begin{array}{l}\text { Home and } \\
\text { community- } \\
\text { based care }\end{array}$ \\
\hline
\end{tabular}

Source: Aday (2001, Figure 5.1, 118). Copyright (C) 2001. This material is used by permission of John Wiley \& Sons, Inc.

Figure 2: U.S. healthcare service continuum [5] 


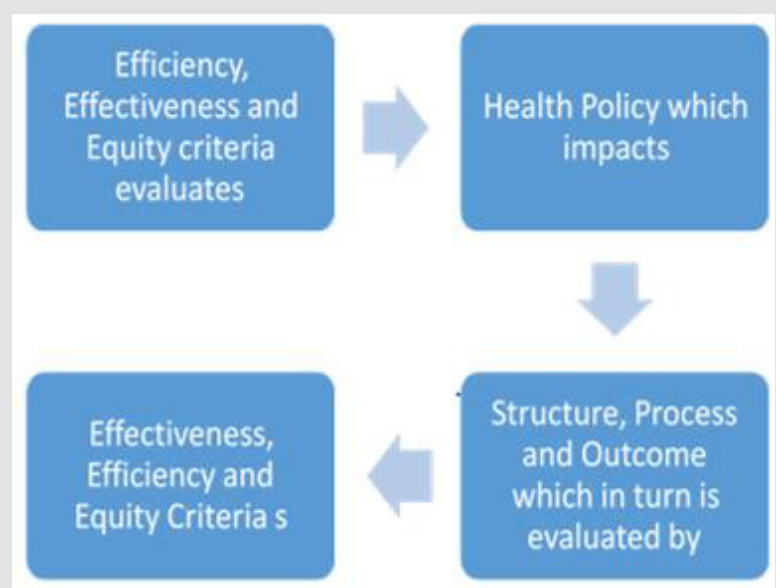

Figure 3: The framework of the model helps evaluate health care service, program, and policy through interrelation of model constructs [5].

Overall, it helps analyze (Figure 4 Appendix) the impact of the healthcare delivery system, other patient characteristics on the overall health and wellbeing of the population it was developed to serve [4]. It helps understand the impact and analyze the impact of the healthcare delivery system and personal characteristics/ demographic characteristics at both population-level, i.e., population perspective, and clinical level, i.e., clinical perspective including system, individual or organizational level [4]. The model can be studied at both the macro and micro levels to determine the outcome [4]. Overall health and wellbeing could be measured by measuring health indicators. Finally, effectiveness, efficiency, and equity criteria help understand and evaluate if the existing policy, intervention, or practice are efficient, equitable, and effective [4]. Effectiveness, efficiency, and equity are often complementary [4].

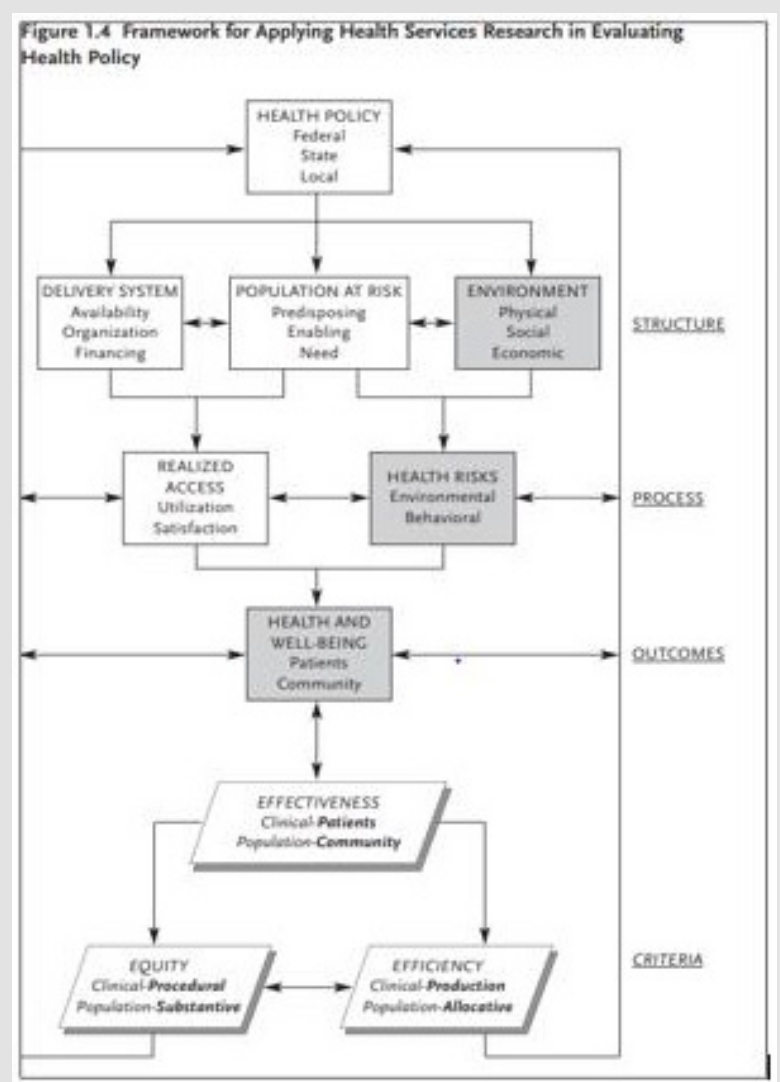

Figure 4: Andersen and Aday final phase model [5]. 
Effectiveness in clinical perspective is medical treatment effectiveness, while a population perspective its medical and non-medical (environmental and behavioral) effectiveness of intervention [4]. On the other hand, efficiency means cost-benefit analysis or cost-effectiveness, or cost-utility analysis [4]. It means if indeed within the limited resources, the available treatment is effective and low at the cost compared to other alternatives [4]. Finally, Equity Helps determine if the effective and efficient intervention is available equally or distributed equally to all? [4], Is there procedural fairness at the structural and process level to make this effective and efficient intervention available to all groups? The Model helps determine the performance of the U.S. healthcare system and policy impact on the healthcare system, as we refer to Figure 3 in Appendix [4]. The application of the structure process and outcome model to determine healthcare quality [29], variation in resources, and impact of delivery system on patient outcomes and utilization [30] determined in the past. The Healthcare system is complex [31].

In such cases, evaluation of either change in infrastructures like telehealth or the characteristics of both patient/provider and systems providing care [32] through the application of Andersen and Aday model is evident in the past. The delivery system or any intervention proposed needs be measured through the lens of effectiveness and efficiency [33]. The model utilizes measures and attributes of the healthcare delivery system like structure, process, and outcome to determine and evaluate the health and well-being of the population it serves. With the model, both the provider and subgroup of problems, including demographic characteristics (predisposing, need, and enabling factors) and its intervention, are evaluated [33]. Including the demographic characteristics in the model helps us understand how target population characteristics needs are addressed by existing system performance or network and how their overall health and well-being are being impacted? [33].

Hence it is crucial to determine while implementing this model, who is the target population of interest? Is it homeless people, children, or doctors protected against COVID-19 infection through the implementation of telehealth, or is its population protected from COVID-19 infection? It is also important to note that effect and outcome at all levels (population and clinical) are essential to analyze as new technology and service might be effective and work at an individual level but might not work at a population level (scale-up problem) as discussed in the book [4]. To fully understand the effect of health programs, interventions, or policy, the impact at each level (Figure 5 in Appendix) is necessary to be determined [4].

\begin{tabular}{|c|c|c|c|c|}
\hline & Structure (inpats) & Process & Outputs & Outcome \\
\hline $\begin{array}{l}\text { Type of } \\
\text { measure }\end{array}$ & $\begin{array}{l}\text { Costs } \\
\text { Resources- staff, } \\
\text { equipenent, buldings, beds }\end{array}$ & $\begin{array}{l}\text { Patient care } \\
\text { Stratepies, plans, polcies } \\
\text { Patient pathway }\end{array}$ & $\begin{array}{l}\text { Hospital activity } \\
\text { No. of complaints } \\
\text { Change in bed } \\
\text { occupancy } \\
\text { Length of stay }\end{array}$ & $\begin{array}{l}\text { Mortality-alive dead } \\
\text { Impairment-pathology, } \\
\text { clinical measures } \\
\text { Disabaity- functional status } \\
\text { Acceptability } \\
\text { Clinical and patient reported } \\
\text { outcome measures } \\
\text { Discharge }\end{array}$ \\
\hline $\begin{array}{l}\text { Example } \\
\text { indicators }\end{array}$ & $\begin{array}{l}\text { Staff time (hours) } \\
\text { Expenditure ( }(€)\end{array}$ & $\begin{array}{l}\text { Patient records, treatment plans, } \\
\text { information leadets, prescription practices } \\
\text { Waiting times }\end{array}$ & $\begin{array}{l}\text { Occupied beddrys } \\
\text { Number of patients } \\
\text { receking treatment } \\
\text { No of complaints }\end{array}$ & $\begin{array}{l}\text { Mortality rate } \\
\text { Clrical and patient reported } \\
\text { outcome measures } \\
\text { Emergency readmission rates }\end{array}$ \\
\hline
\end{tabular}

Figure 5: Indicators and measures illustrate potential predictors and outcomes for the health service utilization and delivery system outcomes [5]. 


\section{Application of Andersen and Aday Model Within Context of Telehealth Utilization}

Studies examining disparity in healthcare access and utilization so far have utilized the model to construct the research variables for outcome measures of healthcare utilization [12]. The indicators of healthcare access and utilization measured are "probability of being uninsured, probability of having any delayed necessary medical care, and probability of having any forgone medical care" [12]. Hence the model can determine the impact of telehealth services on healthcare utilization both at the population and clinical perspective level. Health care utilization measures are the probability of having an emergency department (E.D.) visit, and probability of having any physician visit" [12]. The covariates of the study can be informed by the model [12] categorized into three domains like predisposing factors, enabling factors, need factors. Hence, the model provides information on mechanism through which outcomes like healthcare utilization are impacted other than telehealth intervention as a primary treatment variable.

Studies have applied the model to understand process level barriers of utilization and their impact on the overall quality of health, i.e., under or overuse of healthcare services of a particular specialty $[34,35]$. One study utilizes only process and outcome level data to determine the adequacy/effectiveness of existing healthcare delivery and services [34]. So, telehealth service's effectiveness on the current healthcare delivery system can be measured by applying Andersen and Aday Model in determining impacts on health care service utilization among primary care and preventive care population during COVID-19 [24]. The Anderson and Aday model could be utilized in stages to determine the effectiveness of telehealth utilization [33]. In the first stage, we could use the model to determine the system-level factors impacting telehealth utilization, affecting the overall continuity in healthcare utilization for chronically ill and other preventive services [36]. By doing so, we would measure the system performance and gather existing evidence $[33,25]$.

In the second stage, one can implement the model to determine and establish standard guidelines of the process of care [33] for telemedicine and its utilization. Once the standard guidelines are determined, the indicators for measurements from the guidelines could be established for each construct of the model to establish the quality of telemedicine care or delivery system [33]. In the final stage, the quality outcomes could be utilized to develop strategies for improvement and reanalyze the outcomes after implementing those strategies [33] identified regarding telehealth implementation and utilization. The model could also evaluate a socioeconomically vulnerable group of population [37,24] facing disparity in telehealth utilization within the healthcare system [19]. The model evaluates several factors that make the population vulnerable and uses them to determine its impact on their healthcare utilization [37], as factors that make the group vulnerable might be responsible for the effect on the overall utilization of care [37]. The model application for the vulnerable population could help determine the effect of telehealth healthcare utilization on the health outcomes/status of the group as health status determines utilization [37].

It is vital to understand whether COVID-19 has brought changes in disparities associated with telehealth utilization within any healthcare system $[19,24]$. The U.S. Centers for Disease Control and Prevention recommends utilizing Telehealth services during the pandemic to seek needed care. Hence Andersen and Aday model could help determine the uptake rate of telehealth services through the number of visits via telemedicine and its impact on timely access to care and health care utilization [24]. The model can also help identify potential structure, process, and individual level barriers $[38,39,23]$ that could impact telehealth utilization among the vulnerable population [22] and how it impacts the overall access to primary care [22]. As established prior (Figure 1, Appendix) in this paper, structure and process-level factors impact and can be assessed by the access to health, healthcare utilization, and quality of care components.

It is vital to understand how the pandemic affects the complexity gap between the needs and services of patients for chronic care [32]. The reason behind doing so is to understand the impact on service utilization and overall health and well-being among the population with chronic conditions other non-acute, non-urgent care needs. Hence the model can help determine barriers and facilitators of Telehealth and Remote Patient Monitoring Programs [40,41] to determine effectiveness [22], efficiency, and equity aspects of such [38,39] during COVID-19 pandemic. Overall, the Andersen and Aday model can be utilized to measure the impact of telehealth on healthcare utilization (over/underutilization of needed services), readmission rates for specific condition groups, improved quality of care through telehealth $[21,22,28]$, and impact of telehealth on reducing overall cost of care through improved access to care $[20,21]$.

\section{Conclusion}

Structure, process, and outcome constructs in health services research seem to affect healthcare access, cost, and quality. Hence it is vital to utilize the model to determine what aspects of structure (delivery system, population characteristics) and process (utilization, satisfaction) affect utilization, access outcomes like physicians visit, utilization of proposed interventional services, or use of emergency department visits. Quality of care could help determine if the existing care provision is appropriate or not and could serve as an indicator of access and utilization. Since the constructs of the framework are interrelated, like vulnerable population's need for care and existing system delivery together impact the process of care and the health risks the population carry 
which in turn impacts the overall health of the population, its crucial to utilize the entire model to understand the complex situations that affect telehealth and utilization of care. It is also established that utilization of healthcare and health outcomes serve as an indicator of access to needed healthcare in this paper. Barriers to access to telehealth services impact the overall health outcomes and over or underutilization of needed healthcare. Application of the Andersen and Aday Model to telehealth service utilization and its impact on overall healthcare utilization in health services research can help inform government policies relevant to its effectiveness, equity, and efficiency. The model can also help understand facilitators, barriers for telehealth implementation in the healthcare delivery system. It also helps understand the disparity in health outcomes among the population and specific groups and the quality of healthcare service.

\section{References}

1. Penchansky R, Thomas JW (1981) The concept of access: Definition and relationship to consumer satisfaction. Medical Care 19(2): 127-140.

2. Mazurenko O, Balio CP, Agarwal R, Carroll AE, Menachemi N (2018) The effects of medicaid expansion under the ACA: A systematic review. Health Affairs 37(6): 944-950.

3. (1993) Committee on Monitoring Access to Personal Health Care Services. A model for monitoring access. In Access to health care in America.

4. Aday L, Begley C, Lairson D, Slater C (2004) Evaluating the healthcare system: effectiveness, efficiency, and equity (Third). Health Administration Press.

5. Aday L, Begley C, Lairson D, Slater C (2004) Evaluating the healthcare system: effectiveness, efficiency, and equity (Third). Academy Health.

6. Kullgren JT, McLaughlin CG, Mitra N, Armstrong K (2012) Nonfinancial barriers and access to care for U.S. adults. Health Services Research 47(1 PART 2): 462-485.

7. Starfield B, Shi L, Macinko J (2005) Contribution of primary care to health systems and health. In Milbank Quarterly 83(3): 457-502.

8. Hsu J, Price M, Vogeli C, Brand R, Chernew ME, et al. (2017) Bending the spending curve by altering care delivery patterns: The role of care management within a pioneer ACO. Health Affairs 36(5): 876-884.

9. Chuang E, Pourat, N, Haley LA, Albertson E, Lu C, et al. (2020) Integrating health and human services in california's whole person care medicaid 1115 waiver demonstration. Health Affairs 39(4): 639-648.

10. Kaufman BG, Spivack BS, Stearns SC, Song PH, O’Brien EC (2019) Impact of Accountable Care Organizations on Utilization, Care, and Outcomes: A Systematic Review. In Medical Care Research and Review 76(3): 255290.

11. Henke RM, Karaca Z, Gibson TB, Cutler E, White, C, et al. (2020) Medicaid Accountable Care Organizations and Childbirth Outcomes. Medical Care Research and Review 77(6): 559-573.

12. Chen J, Vargas Bustamante A, Mortensen K, Ortega AN (2016) Racial and ethnic disparities in health care access and utilization under the affordable care act. Medical Care 54(2): 140-146.

13. Marton J, Yelowitz A, Shores M, Talbert JC (2016) Does Medicaid Managed Care Help Equalize Racial and Ethnic Disparities in Utilization? Health Services Research 51(3): 872-891.
14. Benitez JA, Creel L, Jennings J (2016) Kentucky's medicaid expansion showing early promise on coverage and access to care. Health Affairs 35(3): 528-534

15. Frean M, Gruber J, Sommers BD (2017) Premium subsidies, the mandate, and Medicaid expansion: Coverage effects of the Affordable Care Act. Journal of Health Economics 53: 72-86.

16. Raven MC, Niedzwiecki MJ, Kushel M (2020) A randomized trial of permanent supportive housing for chronically homeless persons with high use of publicly funded services. Health Services Research 55(S2): 797-806.

17. Aboumatar HJ, Chang BH, Al Danaf J, Shaear M, Namuyinga R, et al. (2015) Promising practices for achieving patient-centered hospital care: A national study of high-performing U.S. hospitals. Medical Care 53(9): 758-767.

18. Ahmed S, Berzon RA, Revicki DA, Lenderking WR, Moinpour CM, et al. (2012) The use of patient-reported outcomes (PRO) within comparative effectiveness research: Implications for clinical practice and health care policy. Medical Care 50(12): 1060-1070.

19. Cantor JH, McBain RK, Pera MF, Bravata DM, Whaley CM (2021) Who Is (and Is Not) Receiving Telemedicine Care During the COVID-19 Pandemic. American Journal of Preventive Medicine 0(0): 1-5.

20. Cortelyou Ward K, Atkins DN, Noblin A, Rotarius T, White P, et al. (2020) Navigating the digital divide: Barriers to telehealth in rural areas. Journal of Health Care for the Poor and Underserved 31(4): 1546-1556.

21. Grundstein MJ, Sandhu HS, Cioppa Mosca JM (2020) Pivoting to Telehealth: the HSS Experience, Value Gained, and Lessons Learned. HSS Journal 16: 164-169.

22. Jacobs EA, Ogedegbe O, Fihn SD (2020) Elective Care and Health Services Research in the COVID-19 Era. JAMA Network Open 3(11): e2025731.

23. Weber E, Miller SJ, Astha V, Janevic T, Benn E (2020) Characteristics of telehealth users in NYC for COVID-related care during the coronavirus pandemic. Journal of the American Medical Informatics Association 27(12): 1949-1954.

24. Whaley CM, Pera MF, Cantor J, Chang J, Velasco J, et al. (2020) Changes in Health Services Use Among Commercially Insured U.S. Populations During the COVID-19 Pandemic. JAMA Network Open 3(11): e2024984.

25. Schweiberger K, Hoberman A, Iagnemma J, Schoemer P, Squire, J, et al. (2020) Practice-level variation in telemedicine use in a pediatric primary care network during the COVID-19 pandemic: Retrospective analysis and survey study. Journal of Medical Internet Research 22(12): e24345.

26. Moss HE, Lai KE, Ko MW (2020) Survey of Telehealth Adoption by Neuroophthalmologists During the COVID-19 Pandemic: Benefits, Barriers, and Utility. Journal of Neuro-Ophthalmology: The Official Journal of the North American Neuro-Ophthalmology Society 40(3): 346-355.

27. Hollander JE, Carr BG (2020) Virtually Perfect? Telemedicine for Covid-19. New England Journal of Medicine 382(18): 1679-1681.

28. Hughes HE, Hughes TC, Morbey R, Challen K, Oliver I, et al. (2020) Emergency department use during COVID-19 as described by syndromic surveillance. Emergency Medicine Journal 37(10): 600-604.

29. Hoenig H, Duncan PW, Horner RD, Reker DM, Samsa GP, et al. (2002) Structure, process, and outcomes in stroke rehabilitation. Medical Care 40(11): 1036-1047.

30. Tarlov AR, Ware JE, Greenfield S, Nelson EC, Perrin E, et al. (1989) The Medical Outcomes Study: An Application of Methods for Monitoring the Results of Medical Care. JAMA: The Journal of the American Medical Association 262(7): 925-930. 
31. Bodenheimer T, Grumbach $\mathrm{K}$, Lo B, Kierszenbaum AL, Tres L, et al. (2012) Understanding health policy: A clinical approach.

32. Grembowski D, Schaefer J, Johnson K, Fischer H, Moore S (2014) A Conceptual Model of the Role of Complexity in the Care of Patients with Multiple Chronic Conditions on JSTOR. Medical Care 52(3): S7-S14.

33. DuPlessis HM, Inkelas M, Halfon N (1998) Assessing the performance of community systems for children. In Health services research 33(4): $1111-1142$.

34. Brook RH (1996) Measuring Quality of Care. New England Journal of Medicine 335(13): 966-970.

35. McGlynn EA, Asch SM, Adams J, Keesey J, Hicks J, et al. (2003) The Quality of Health Care Delivered to Adults in the United States. New England Journal of Medicine 348(26): 2635-2645.

36. Brook RH, McGlynn EA, Cleary PD (1996) Measuring Quality of Care New England Journal of Medicine 335(13): 966-970.

ISSN: 2574-1241

DOI: 10.26717/BJSTR.2021.38.006114

Naiya Patel. Biomed J Sci \& Tech Res

(C) (P) This work is licensed under Creative

Submission Link: https://biomedres.us/submit-manuscript.php
37. Gelberg L, Andersen RM, Leake BD (2000) The Behavioral Model for Vulnerable Populations: application to medical care use and outcomes for homeless people. In Health services research 34(6): 1273-1302.

38. Bodenheimer Thomas, Wagner EH, Grumbach K (2002) Improving primary care for patients with chronic illness. In Journal of the American Medical Association 288(14): 1775-1779.

39. Bodenheimer Thomas, Wagner EH, Grumbach K (2002) Improving primary care for patients with chronic illness: The chronic care model, Part 2. In Journal of the American Medical Association 288(15): 19091914.

40. Song Z, Ji Y, Safran DG, Chernew ME (2019) Health Care Spending, Utilization, and Quality 8 Years into Global Payment. New England Journal of Medicine 381(3): 252-263.

41. Annis T, Pleasants S, Hultman G, Lindemann E, Thompson JA, et al. (2020) Rapid implementation of a COVID-19 remote patient monitoring program. Journal of the American Medical Informatics Association 27(8): 1326-1330.

$\begin{array}{ll}\text { BIOMEDICAL } & \text { Assets of Publishing with us } \\ \text { RESEARCHES } & \text { - Global archiving of articles } \\ & \text { - Immediate, unrestricted online access } \\ & \text { - Rigorous Peer Review Process } \\ & \text { - Authors Retain Copyrights }\end{array}$

